\title{
Exogenous Nitric Oxide Protects Human Embryonic Stem Cell-Derived Cardiomyocytes against Ischemia/Reperfusion Injury
}

\author{
János Pálóczi,' Zoltán V. Varga, ${ }^{1,2}$ Ágota Apáti, ${ }^{3}$ Kornélia Szebényi, ${ }^{3}$ \\ Balázs Sarkadi, ${ }^{3,4}$ Rosalinda Madonna, ${ }^{5}$ Raffaele De Caterina, ${ }^{5}$ Tamás Csont, ${ }^{1}$ \\ Thomas Eschenhagen, ${ }^{6}$ Péter Ferdinandy, ${ }^{1,2,7}$ and Anikó Görbe ${ }^{1,2,7}$ \\ ${ }^{1}$ Cardiovascular Research Group, Department of Biochemistry, Faculty of Medicine, University of Szeged, Szeged 6720, Hungary \\ ${ }^{2}$ Department of Pharmacology and Pharmacotherapy, Semmelweis University, Budapest 1085, Hungary \\ ${ }^{3}$ Institute of Enzymology, Research Centre for Natural Sciences, Hungarian Academy of Sciences, Budapest 1519, Hungary \\ ${ }^{4}$ MTA-SE Molecular Biophysics Research Group, Semmelweis University, Institute of Biophysics and Radiation Biology, \\ Budapest 1085, Hungary \\ ${ }^{5}$ Department of Neuroscience and Imaging, Center of Excellence on Aging, “G. d'Annunzio" University, 66100 Chieti, Italy \\ ${ }^{6}$ Department of Experimental Pharmacology and Toxicology, University Medical Center Hamburg-Eppendorf, \\ 20246 Hamburg, Germany \\ ${ }^{7}$ Pharmahungary Group, Szeged 6722, Hungary
}

Correspondence should be addressed to Péter Ferdinandy; peter.ferdinandy@pharmahungary.com and Anikó Görbe; gorbe.aniko@med.u-szeged.hu

Received 8 January 2016; Revised 11 April 2016; Accepted 20 April 2016

Academic Editor: Lu Cai

Copyright @ 2016 János Pálóczi et al. This is an open access article distributed under the Creative Commons Attribution License, which permits unrestricted use, distribution, and reproduction in any medium, provided the original work is properly cited.

Background and Aims. Human embryonic stem cell- (hESC-) derived cardiomyocytes are one of the useful screening platforms of potential cardiocytoprotective molecules. However, little is known about the behavior of these cardiomyocytes in simulated ischemia/reperfusion conditions. In this study, we have tested the cytoprotective effect of an NO donor and the brain type natriuretic peptide (BNP) in a screening platform based first on differentiated embryonic bodies (EBs, $6+4$ days) and then on more differentiated cardiomyocytes $(6+24$ days), both derived from hESCs. Methods. Both types of hESC-derived cells were exposed to $150 \mathrm{~min}$ simulated ischemia, followed by $120 \mathrm{~min}$ reperfusion. Cell viability was assessed by propidium iodide staining. The following treatments were applied during simulated ischemia in differentiated EBs: the NO-donor S-nitroso-Nacetylpenicillamine (SNAP) $\left(10^{-7}, 10^{-6}\right.$, and $\left.10^{-5} \mathrm{M}\right), \mathrm{BNP}\left(10^{-9}, 10^{-8}\right.$, and $\left.10^{-7} \mathrm{M}\right)$, and the nonspecific NO synthase inhibitor $\mathrm{N} \omega$ nitro-L-arginine (L-NNA, $\left.10^{-5} \mathrm{M}\right)$. Results. SNAP $\left(10^{-6}, 10^{-5} \mathrm{M}\right)$ significantly attenuated cell death in differentiated EBs. However, simulated ischemia/reperfusion-induced cell death was not affected by BNP or by L-NNA. In separate experiments, SNAP $\left(10^{-6} \mathrm{M}\right)$ also protected hESC-derived cardiomyocytes. Conclusions. We conclude that SNAP, but not BNP, protects differentiated EBs or cardiomyocytes derived from hESCs against simulated ischemia/reperfusion injury. The present screening platform is a useful tool for discovery of cardiocytoprotective molecules and their cellular mechanisms.

\section{Introduction}

Ischemic heart disease is the leading cause of mortality in the Western world; therefore, the development of cardioprotective therapies is currently a main focus of research. In vitro cardiac myocyte-based drug-screening platforms are widely used, especially at the early stage of the development of cardioprotective agents. However, these assays are based on cardiomyoblast cell lines or primary neonatal and adult cardiac myocytes [1] and thus have major limitations, including a low proliferation capacity, uncontrolled stress during cell isolation, low throughput, and poor predictability 
of the assays towards in vivo efficacy [2]. Moreover, the relationship between drug responses from animal-derived primary cardiomyocytes and their human counterparts may be significantly different [3]. Human embryonic stem cells (hESCs) are capable of differentiating towards cardiac lineages [4]; therefore, hESCs provide a promising source of cardiomyocytes for in vitro drug screening $[5,6]$. In addition, hESCs may also provide new tools for regenerative therapies [7-9].

Despite the encouraging results and the enormous potential of the hESC-derived cardiomyocytes, several complications need to be overcome regarding their therapeutic utilization, such as ethical problems, tumor formation, and immunoreactivity. Moreover, it has been demonstrated that the survival of implanted cells is enormously reduced after transplantation [10-12], with these cells undergoing a significant cell death within the first 24 hours [13]. A plausible reason for this effect is the unfavorable microenvironment the grafted cells face when injected into the ischemic host myocardium. Characterization of these cells in an ischemia/ reperfusion test system thus would be important, since little is known about the ischemic tolerance of hESC-derived cardiomyocytes.

We have previously shown that the nitric oxide donor S-nitroso-n-acetylpenicillamine (SNAP) and the particulate guanylate cyclase activator B-type natriuretic peptide (BNP) exert a cytoprotective effect against simulated ischemia/ reperfusion (SI/R) injury in primary neonatal rat cardiomyocytes [14]. More recently, the cytoprotective effect of SNAP has been shown in mouse embryonic stem cell- (mESC-) derived cardiomyocytes subjected to SI/R treatment [15]. This protection occurs via the activation of protein kinase $G$ (PKG) and stimulation of its downstream signal transduction pathway, which leads to increased cell viability against SI/R injury [14-17]. However, this cytoprotective effect of SNAP and BNP against SI/R injury has not been explored as yet in human cardiomyocytes derived from hESCs.

Therefore, the aim of this present study was to test whether the nitric oxide donor SNAP and the particulate guanylate cyclase activator BNP can protect hESC-derived cardiomyocytes against SI/R injury.

\section{Methods}

2.1. Human Embryonic Stem Cell Culture. The CAG promoter driven eGFP expressing human HUES9 stem cell culture (Ethic license: Hungarian Committee of Human Reproduction; 31681-1/2004-1016EHR12534-0/20091016EHR; ES2HEART consortium) $[18,19]$ was dispersed by $0.5 \mathrm{mg} / \mathrm{mL}$ collagenase type IV (Gibco, Invitrogen; Carlsbad, CA, USA) dissolved in KnockOut ${ }^{\mathrm{TM}}$ Dulbecco's Modified Eagle Medium (Gibco). Subsequently, cells were maintained in cell suspension culture for 6 days in KnockOut Dulbecco's Modified Eagle Medium (Gibco), supplemented with 20\% embryonic stem cell-qualified fetal bovine serum (Gibco), $1 \%$ nonessential amino acids, $1 \%$ L-glutamine (Gibco), and $0.2 \%$ beta-mercaptoethanol (Gibco). To allow clump formation, cell attachment was hampered by using polyhema ( $5 \mathrm{mg} / \mathrm{mL}$, Sigma; St. Louis, MO, USA) coated surface. After
6 days, the formation of small clumps was observed which are designated as embryonic bodies (EBs).

2.2. Differentiation of $E B s$ and Cardiomyocytes Derived from Human Embryonic Stem Cells. Six-day-old EBs were seeded onto gelatin-coated coverslips in 24-well plates. 5-10 EBs were plated into each well. Differentiation of EBs was supported by differentiating media containing Dulbecco's Modified Eagle Medium (Sigma) supplemented with 15\% fetal bovine serum (Gibco). EBs were kept under normal conditions (at $37^{\circ} \mathrm{C}$, in $95 \%$ air and $5 \% \mathrm{CO}_{2}$ gas mixture) for 4 days prior to $\mathrm{SI} / \mathrm{R}$ experiments.

In separate experiments, hESC-derived EBs were maintained in differentiating medium for 24 days. At this stage of their differentiation, spontaneous contractions were observed as the sign of the formation of mature cardiac tissues, and these areas were designated as cardiomyocyterich region of EBs.

2.3. Real-Time PCR Analysis of Differentiated EBs. Cardiacoriented differentiation of the cells was documented in differentiated EBs by real-time quantitative PCR analysis. Total RNA was isolated from cells using TRIzol ${ }^{\mathrm{TM}}$ reagent (Invitrogen; Carlsbad, CA, USA). Subsequently, cDNA samples were prepared from $1 \mu \mathrm{g}$ total RNA using the Promega Reverse Transcription System Kit (Promega Corp.; Fitchburg, WI, USA). All these steps were performed according to the manufacturer's instructions. For real-time quantitative PCR, the following predeveloped TaqMan ${ }^{\circledR}$ assays were purchased from Applied Biosystems (Thermo Fisher Scientific; Waltham, MA, USA): octamer-binding transcription factor 4 (OCT4) and the divergent homeodomain protein NANOG as undifferentiated stem cell markers [20-22], BRACHYURY as mesoderm marker [23], the homeobox protein NKX2.5 and the zinc finger transcription factor GATA4 as early markers of cardiac differentiation $[24,25]$, and activated leukocyte cell adhesion molecule (CD166, ALCAM) as a marker of cardiomyocytes [26]. P0 ribosomal protein was used as endogenous control for quantification. Real-time PCR analyses were carried out using the StepOne ${ }^{\mathrm{TM}}$ Real-Time PCR System (Applied Biosystems), according to the manufacturer's instructions. The fold changes of mRNA in experimental and control cells were determined using the $2^{-\Delta \Delta \mathrm{Ct}}$ method. Relative mRNA levels were presented as mean \pm SEM of 3 independent experiments.

2.4. Immunofluorescence. In order to test the specificity of CAG-driven eGFP expression during cardiac differentiation, immunostaining of cardiac troponin I (cTnI) was performed in $6+24$-day-old adherent EBs. Samples were fixed with 4\% paraformaldehyde in Dulbecco's modified phosphate buffered saline (D-PBS, Sigma) for $15 \mathrm{~min}$ at room temperature, followed by three washing steps with D-PBS. To block nonspecific antibody binding, samples were incubated in D-PBS containing $2 \mathrm{mg} / \mathrm{mL}$ bovine serum albumin, $1 \%$ fish gelatin, $5 \%$ goat serum, and $0.1 \%$ Triton-X 100 for $1 \mathrm{~h}$ at room temperature. The samples were then incubated with primary antibodies (monoclonal mouse anti-cTnI, Sigma) 


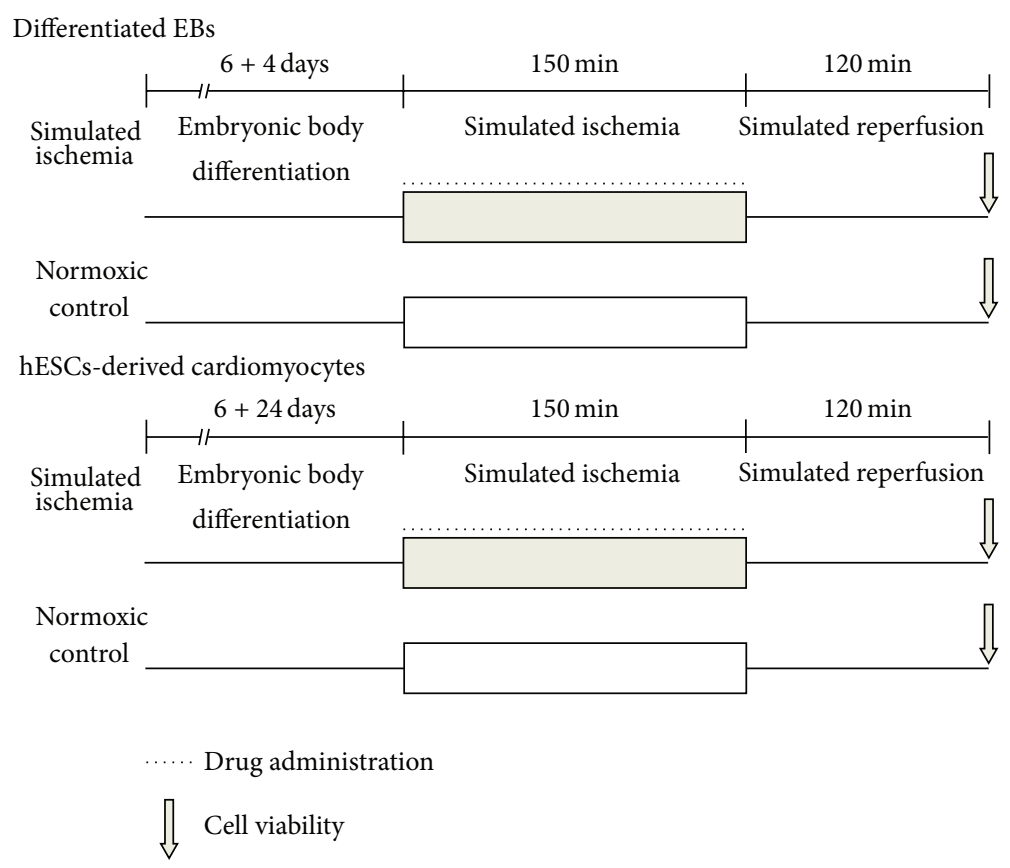

FIGURE 1: Experimental design of simulated ischemia (SI) and reperfusion (R). hESC-derived EBs (6+4 days of differentiation) and differentiated cardiomyocytes ( $6+24$ days of differentiation) were exposed to $150 \mathrm{~min}$ SI, followed by $120 \mathrm{~min}$ R. Cell viability was assessed by propidium iodide staining. The following treatments were applied during SI in differentiated EBs ( $6+4$ days of differentiation): the NOdonor S-nitroso-N-acetylpenicillamine (SNAP) $\left(10^{-7}, 10^{-6}\right.$, and $\left.10^{-5} \mathrm{M}\right), \mathrm{BNP}\left(10^{-9}, 10^{-8}\right.$, and $\left.10^{-7} \mathrm{M}\right)$, and the nonspecific nitric oxide (NO) synthase inhibitor $\mathrm{N} \omega$-nitro-L-arginine (L-NNA, $10^{-5} \mathrm{M}$ ). In case of the hESC-derived cardiomyocytes $\left(6+24\right.$ days of differentiation), $10^{-6} \mathrm{M}$ SNAP was applied during SI. Viability data were normalized to the cardiac specific CAG-driven eGFP fluorescence.

at the dilution of $1: 500$ for $1 \mathrm{~h}$ at room temperature. After washing with D-PBS, the cells were incubated with secondary antibodies (Alexa Fluor 568-conjugated goat antimouse antibody, Invitrogen) for $1 \mathrm{~h}$ at room temperature. Secondary antibodies were diluted in the blocking solution at $1: 250.4^{\prime}, 6$-Diamidino-2-phenylindole-2 $\mathrm{HCl}$ (DAPI, Invitrogen) was used for nuclear staining $(10 \mu \mathrm{M}$, for $10 \mathrm{~min}$ in D-PBS). The stained samples were examined by an Olympus fluorescence microscope.

2.5. Experimental Groups. For cell viability experiments, hESC-derived cells were tested under normoxic condition or were subjected to SI (Figure 1). In normoxic conditions, the differentiating medium was replaced with a normoxic solution (in mM: $\mathrm{NaCl} 125, \mathrm{KCl} 5.4, \mathrm{NaH}_{2} \mathrm{PO}_{4} 1.2, \mathrm{MgCl}_{2}$ 0.5, HEPES 20, glucose 15, taurine 5, $\mathrm{CaCl}_{2} 1$, creatine 2.5, BSA $0.1 \%, \mathrm{pH} 7.4$, and $310 \mathrm{mOsm} / \mathrm{L}$ ) and cells were incubated in a normoxic incubator at $37^{\circ} \mathrm{C}$ for $2.5 \mathrm{~h}$. Regarding ischemic conditions, the cells were subjected to SI by incubating them in hypoxic solution (in $\mathrm{mM}$ : $\mathrm{NaCl} 119, \mathrm{KCl} 5.4, \mathrm{MgSO}_{4} 1.3$, $\mathrm{NaH}_{2} \mathrm{PO}_{4}$ 1.2, HEPES 5, $\mathrm{MgCl}_{2} 0.5, \mathrm{CaCl}_{2} 0.9$, Na-lactate 20, BSA $0.1 \%, 310 \mathrm{mOsm} / \mathrm{L}$, and $\mathrm{pH}=6.4$ ) and exposed to a constant flow of a mixture of $95 \% \mathrm{~N}_{2}$ and $5 \% \mathrm{CO}_{2}$ for 2.5 hours at $37^{\circ} \mathrm{C}$. Cells were subjected to the following treatments during SI: (1) untreated control; (2) SNAP $\left(10^{-7}\right.$, $10^{-6}$, and $\left.10^{-5} \mathrm{M}\right)$ (Sigma); (3) brain type natriuretic peptide32 (BNP, $10^{-9}, 10^{-8}$, and $10^{-7} \mathrm{M}$ ) (American Peptides); (4) NOS inhibitor N-nitro-L-arginine (L-NNA, $10^{-5} \mathrm{M}$ ) (Sigma).
Concentrations of the compounds were selected according to our previous data $[14,15]$.

At the second set of experiments, cardiomyocytes derived from hESCs were subjected to the following treatments during SI: (1) untreated control; (2) SNAP $\left(10^{-6} \mathrm{M}\right)$.

Either normoxic or SI treatments were followed by $2 \mathrm{~h}$ reperfusion, when the previously applied solutions were replaced with differentiating medium, and the cells were maintained in a normoxic incubator, gassed with 95\% air and $5 \% \mathrm{CO}_{2}$ at $37^{\circ} \mathrm{C}$.

2.6. Cell Viability Measurements. At the first set of experiments with differentiated EBs derived from hESCs, after simulated reperfusion, cell viability was assessed by propidium iodide (PI) assay as described previously [15]. Briefly, the growth medium was removed, and the cells were washed with PBS twice and incubated with PI (50 $\mu \mathrm{M}$, Sigma) for $7 \mathrm{~min}-$ utes. Each experiment included a digitonin $\left(10^{-4} \mathrm{M}\right.$, Sigma) treated positive control. Then, PI solution was replaced with fresh PBS and fluorescence intensity of each well was detected by a fluorescent plate reader using $544 \mathrm{ex} / 610 \mathrm{em}$ filters (FluoStar Optima, BMG Labtech, Thermo Fisher Scientific). PI intensity reflecting cell death was evaluated in the cardiomyocyte-rich region. Since the elevation of eGFP expression is associated with cardiac-oriented differentiation of this hESCs model, the evaluation of cardiomyocyte committed regions was performed manually on each plate by detecting eGFP expression driven by the CAG promoter 

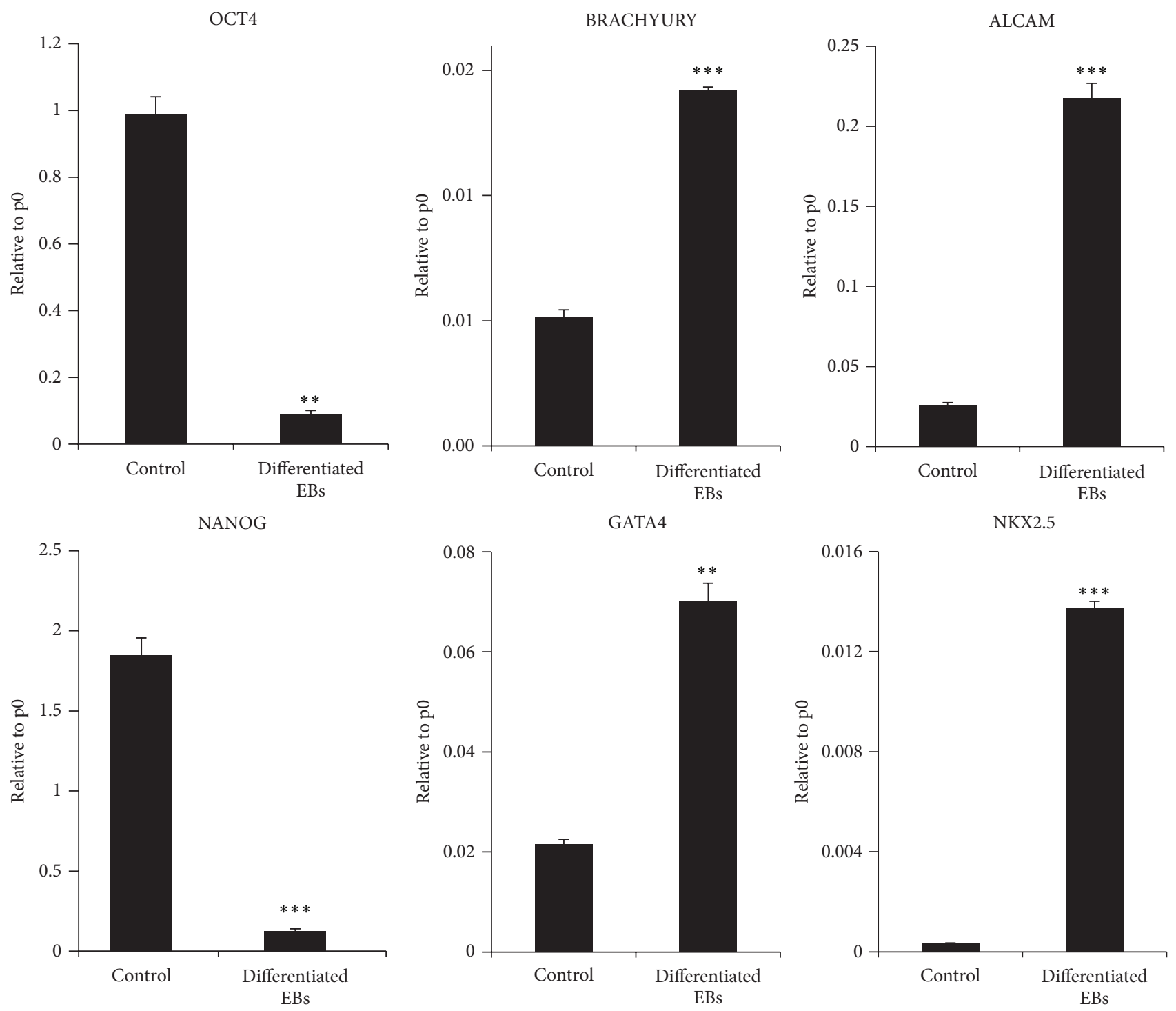

(a)

(b)

FIgURE 2: Real-time PCR analysis of differentiated EBs $(6+4$ days of differentiation). OCT4 and NANOG pluripotency markers were downregulated (a), whereas mesodermal (BRACHYURY) and early and later cardiac markers (NKX2.5, GATA4, and ALCAM) were upregulated (b) as compared to the undifferentiated human HUES9 embryonic stem cell line control. Data are expressed as mean \pm SEM; ${ }^{* *} p<0.01$, and ${ }^{* * *} p<0.001$, differentiated EBs versus undifferentiated control; Student $t$-test, $n=2$.

(Supplemental Figure 1, in Supplementary Material available online at http://dx.doi.org/10.1155/2016/4298945). The cytoprotective effect of different compounds was compared to simulated ischemic control groups, where cell death was designated as 100 percent.

At the second set of experiments, cardiomyocytes derived from hESCs underwent SI/R procedure similar to other groups. Cell viability was assessed by the above-described method.

2.7. Statistical Analysis. Results are expressed as mean \pm SEM. Unpaired $t$-test and one-way analysis of variance (ANOVA) followed by Fisher's least significant difference
(LSD) post hoc tests were used to determine differences in mean values between the experimental groups. Differences were considered significant at $p<0.05$.

\section{Results}

3.1. Cardiac Differentiation of EBs. Real-time quantitative PCR analysis confirmed the cardiac-oriented development of cells in differentiated EBs. Both OCT4 and NANOG pluripotency markers were downregulated in the differentiated EBs as compared to the undifferentiated human HUES9 embryonic stem cell line control (Figure 2). Additionally, the expression of mesodermal (BRACHYURY) and early cardiac 
TABLE 1: Cell death of both differentiated EBs $(6+4$ days of differentiation) and cardiomyocytes derived from hESCs $(6+24$ days of differentiation) exposed to normoxia or SI: representative results obtained from one plate. Data are expressed as mean \pm SEM; $p<0.05$ normoxia versus SI; unpaired $t$-test, $n=5-6$ in both groups.

(a) The effect of SI/R on cell death of differentiated EBs derived from hESCs $(6+4$ days of differentiation $)$

\begin{tabular}{lcc}
\hline Group & Mean RFU \pm SEM & $p$ value \\
\hline Normoxia & $1141 \pm 69.83$ & $p=0.0019$ \\
SI & $3624 \pm 516.2$ & (unpaired $t$-test) \\
\hline
\end{tabular}

(b) The effect of SI/R on cell death of hESC-derived cardiomyocytes $(6+24$ days of differentiation)

\begin{tabular}{lcc}
\hline Group & Mean RFU \pm SEM & $p$ value \\
\hline Normoxia & $65817 \pm 10272$ & $p=0.0027$ \\
SI & $137045 \pm 17555$ & (unpaired $t$-test) \\
\hline
\end{tabular}
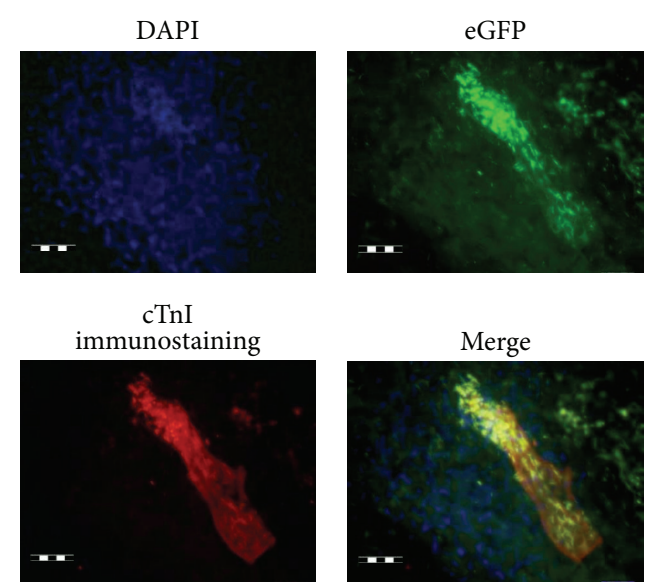

FIGURE 3: Colocalization of cTnI and enhanced CAG-driven eGFP signals in cardiomyocytes derived from hESCs $(6+24$ days of differentiation). Scale bar: $200 \mu \mathrm{m}$.

markers (NKX2.5 and GATA4) were elevated at this stage of differentiation. Moreover, the cardiac specific ALCAM expression was also upregulated as compared to the control.

The specificity of CAG-driven eGFP expression during cardiac differentiation was also documented. In later stage EBs (6 + 24 days), an enhanced eGFP expression was observed in cTnI positive cardiomyocytes derived from hESCs, as confirmed by the colocalization of both signals obtained by immunostaining of cTnI (Figure 3).

3.2. Cell Viability after SI/R. The cytoprotective effect of the NO-donor SNAP that activates soluble guanylate cyclase (sGC) was tested in the model of simulated ischemia (SI). Reperfusion-induced cell death was monitored in differentiated EBs as well as in cardiomyocytes derived from hESCs. We found that SI followed by reperfusion caused significantly higher cell death in differentiated EBs or cardiomyocytes than in time-matched controls kept under normoxic conditions (Table 1).

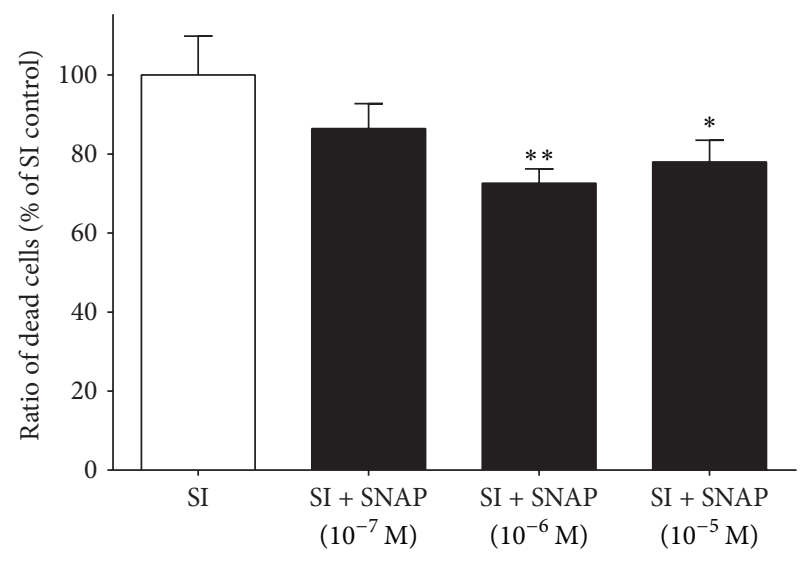

FIGURE 4: Effect of SNAP on cell viability of differentiated EBs derived from hESCs $(6+4$ days of differentiation). SNAP was applied during SI. Data are expressed as mean \pm SEM; ${ }^{*} p<0.05$ SNAP treated versus SI control; ${ }^{* *} p<0.01$ SNAP treated versus SI control; one-way ANOVA followed by Fischer LSD post hoc test, $n=8$ in each group.

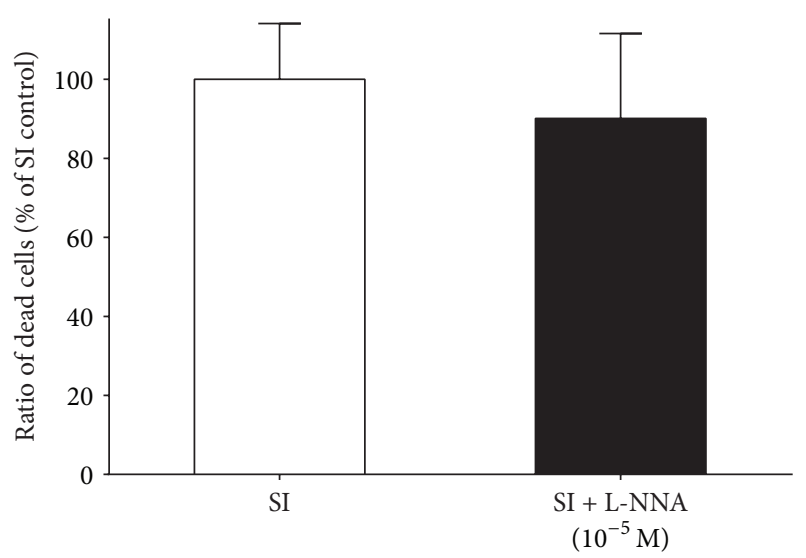

FIGURE 5: Effect of L-NNA on cell viability of differentiated EBs derived from hESCs $(6+4$ days of differentiation). L-NNA was applied during SI. Data are expressed as mean \pm SEM; unpaired $t$ test, $n=4$ in each group.

In differentiated EBs, cell death was significantly decreased by SNAP in a concentration-dependent manner when applied during the SI period (Figure 4).

The endogenous NO production was abolished by the administration of the nonselective NOS inhibitor L-NNA at $10^{-5} \mathrm{M}$ concentration. The presence of L-NNA alone did not influence cell death after SI (Figure 5). BNP, an activator of particulate guanylate cyclase tested at $10^{-9}, 10^{-8}$, and $10^{-7} \mathrm{M}$ concentrations, did not influence cell death significantly (Figure 6).

In order to confirm the cytoprotective effect of SNAP, it was administered to hESC-derived cardiomyocytes. SNAP, as compared to vehicle, attenuated cell death in the hESCderived cardiomyocytes at $10^{-6} \mathrm{M}$ concentration (Figure 7). 


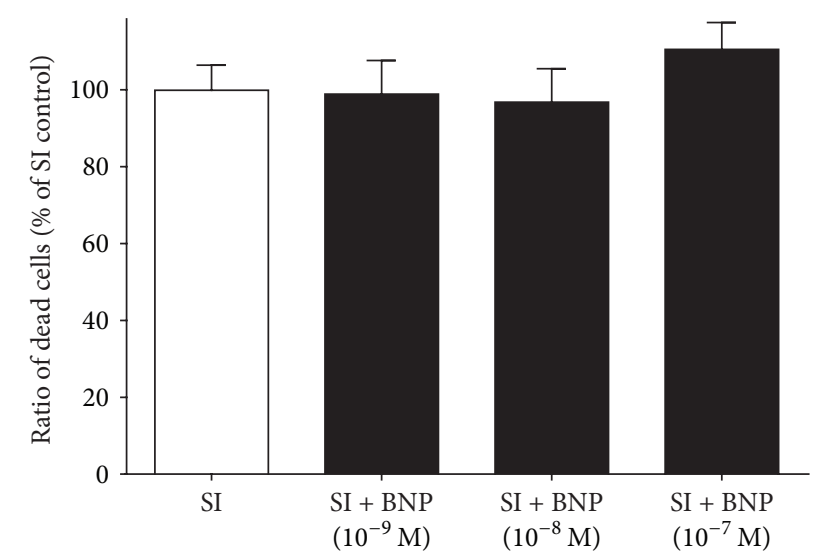

FIGURE 6: Effect of BNP on cell viability of differentiated EBs derived from hESCs ( $6+4$ days of differentiation). BNP was applied during SI. Data are expressed as mean $\pm \mathrm{SEM}, n=8$ in each group.

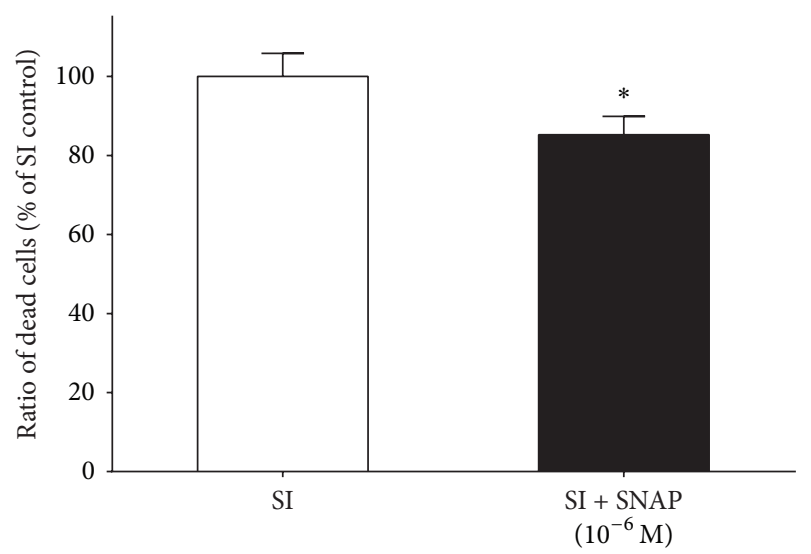

FIGURE 7: Effect of SNAP on cell viability of hESC-derived cardiomyocytes $(6+24$ days of differentiation). SNAP was applied during SI. Data are expressed as mean \pm SEM; ${ }^{*} p<0.05$ SNAP treated versus SI control; one-way ANOVA followed by Fischer LSD post hoc test, $n=8$ in each group.

\section{Discussion}

Here, we show for the first time that the NO-donor SNAP is able to provide cardiocytoprotective effect against SI/Rinduced cell death in a model of differentiated human EBs as well as in contracting cardiomyocytes derived from hESCs. Moreover, this study is the first demonstration of a hESC-based drug-screening platform that is able to identify cardioprotective compounds against SI/R injury.

Currently used primary cardiomyocyte-based or cardiomyoblast cell line-based drug-screening platforms have many limitations for their utilization. The disadvantages of these assays strongly limit their applicability in preclinical research. Primary neonatal cardiomyocytes are widely used to test cardioprotective drugs; however, results may vary due to culture variability introduced by the isolation procedure or the limited proliferation [27]. Adult cardiomyocytes are suitable to study individual cells, and particularly the pharmacological properties of different ion channels can be examined using this model. However, such cells require special conditions during culturing, especially laminin coated surface, which is indispensable for proper attachment and cell survival [2]. Cell lines are preferable test systems for drug screening, however presenting several limitations. The H9c2 cardiomyoblast line shows different phenotype even from neonatal and adult cardiac myocytes, and additionally spontaneous electric activity and sarcomeric structure cannot be observed in them [28]. Since the translational value of hESCbased platforms for representing human conditions may be substantially higher than the abovementioned cell culture models, here we validated a hESC-derived cardiomyocytebased drug-screening platform to test cardioprotective agents by using the well-known cardiocytoprotective NO-donor SNAP [14, 15, 29-32].

In our experiments, we found that the NO-donor SNAP increased the viability of differentiated EBs derived from hESCs, subjected to SI/R. This protective effect was dosedependent, showing the same dose response characteristics as found in neonatal rat cardiomyocytes [14] exposed to SI/R. Our research had shown that NO exerts direct cardiocytoprotection via cGMP-PKG signaling pathway. Moreover, another study on normoxic, neonatal rat cardiac myocyte showed that SNAP caused significant necrosis at $1 \mathrm{mM}$ concentration (no significant changes at 10 and $100 \mu \mathrm{M}$ ), but a bell-shaped effect on apoptosis was observed, that is, significant increase at $100 \mu \mathrm{M}$ and no effect at $10 \mu \mathrm{M}$ and $1 \mathrm{mM}$ [33].

Similar results were presented by our group on mouse embryonic stem cell-derived cardiomyocytes, where NO had concentration-dependent direct cytoprotective action and soluble guanylate cyclase, PKG, and KATP channels play a role in the downstream pathway of SNAP-induced cytoprotection [15]. Hsieh et al. showed recently that short pretreatment with $\mathrm{NO}$ donor $\left(\mathrm{NaNO}_{2}\right)$ combined with hypoxia protects neonatal cardiac myocyte but not cardiac fibroblast from hypoxic injury, and apoptosis decreased in human ES-derived cardiac myocytes [34]. These results further suggest that NO donors may protect stem cells implanted into ischemic areas of the myocardium. Additionally, it has been shown that NO is able to facilitate ESC differentiation and cardiomyogenesis [35]. To investigate if endogenous $\mathrm{NO}$ affects ischemic tolerance of differentiated EBs derived from hESCs, a nonspecific NOS inhibitor, L-NNA, was given during SI. L-NNA did not affect cell viability after SI/R injury of differentiated EBs, indicating that ischemic tolerance of these cells is not altered by endogenous NO. However, local NO concentration largely depends on the ratio of $\mathrm{NO}$ and local superoxide production (see, for reviews, Ferdinandy and Schulz, 2003; Andreadou et al., 2015) [36, 37]. Bioavailability of NO also depends on NO synthase (NOS) expression, and previously it was shown that NOS expression has a developmental stage-dependent expression pattern in rat mouse embryos. Mouse EBs treated with NOS inhibitor were prone to less differentiate after embryonic age D-13. Here, we have shown, in human ESderived cardiac myocytes, that NO has a direct cytoprotective effect in early and more differentiated stage.

Intracellular biosynthesis of cGMP can be catalyzed by both soluble (sGC) and particulate (pGC) guanylate cyclase. 
The activation of the same intracellular signaling pathway was achieved by administration of BNP (activator of pGC) which is an effective cardioprotective peptide. We have previously shown that exogenously administered BNP reduced cell death after SI/R injury in neonatal rat cardiomyocyte cultures [14] and reduced infarct size at $\mathrm{nM}$ concentration range in rat hearts [38]. In agreement with our previous finding in a mouse ESC-derived cardiomyocyte model [15], the exogenously administered $\mathrm{BNP}$ was not protective against SI/R-induced cell death in differentiated EBs. The lack of protection may be attributed to the low expression of the NPR-A receptor (specific for BNP) during hESC differentiation [39]. In another study, BNP significantly increased the number of apoptotic neonatal cardiac myocytes subjected to mild hypoxic stimulus $\left(3 \% \mathrm{O}_{2}\right)$ in a concentration-dependent manner $(0.01 ; 0.1 ; 1 \mu \mathrm{mol} / \mathrm{L})$; however, it had no significant effect on the number of necrotic cells [40].

hESC differentiation with suspension EB method results in around 30\% cardiac myocyte population [41]; however, the efficacy of cardiac differentiation may vary depending on stem cell line or experimental circumstances $[7,8,42-$ 44]. Here, in our study, we were able to selectively investigate cardiac myocyte population in the embryonic bodies by using eGFP overexpression, which enhances the specificity of screening platform.

In summary, here, we demonstrate for the first time that SNAP, but not BNP, protects differentiated human EBs or cardiomyocytes against SI/R injury. Our findings also suggest that hESC-derived differentiated EBs containing early cardiac committed cells may serve as a screening platform for the discovery of cardiocytoprotective molecules; additionally, the present platform is suitable for testing the cardiac myocyte population of the EBs.

\section{Competing Interests}

The authors declare that they have no competing interests.

\section{Authors' Contributions}

Ágota Apáti and Balázs Sarkadi provided hESC-derived EBs. János Pálóczi and Zoltán V. Varga cultured EBs and performed SI/R experiments and viability measurements. Ágota Apáti and Kornélia Szebényi carried out the qRT-PCR experiments and immunostaining of hESC-derived cardiomyocytes. János Pálóczi, Zoltán V. Varga, and Kornélia Szebényi analyzed and interpreted the data, made the statistical analysis, and prepared the figures. János Pálóczi, Anikó Görbe, and Péter Ferdinandy drafted the paper. Balázs Sarkadi, Tamás Csont, Rosalinda Madonna, Raffaele De Caterina, and Thomas Eschenhagen participated in the study design and coordination and critically revised the paper. Anikó Görbe and Péter Ferdinandy conceived the study and coordinated and supervised it. All authors read and approved the final paper. Péter Ferdinandy and Anikó Görbe contributed equally to this work.

\section{Acknowledgments}

The parental HUES9 cell line was kindly provided by Douglas Melton, HHMI. This work has been supported primarily by a grant from NKFP 07 1-ES2HEART-HU (OM-00202/2007) and by other grants: National Development Agency, New Hungary Development Plan (TÁMOP-4.2.2-08/1/2008-0013, TÁMOP-4.2.1/B-09/1/KONV-2010-005); OTKA PD-106001; "National Excellence Program" (TÁMOP-4.2.4.A/2-11/12012-0001). Anikó Görbe holds a "János Bolyai Fellowship" from the Hungarian Academy of Sciences. János Pálóczi held an "SZTE Talent Fellowship" from the University of Szeged. Péter Ferdinandy was a Szentágothai fellow of the National Program of Excellence (TAMOP 4.2.4.A/2-11-1-2012-0001).

\section{References}

[1] A. Hansen, A. Eder, M. Bönstrup et al., "Development of a drug screening platform based on engineered heart tissue," Circulation Research, vol. 107, no. 1, pp. 35-44, 2010.

[2] E. A. Woodcock and S. J. Matkovich, "Cardiomyocytes structure, function and associated pathologies," International Journal of Biochemistry and Cell Biology, vol. 37, no. 9, pp. 1746-1751, 2005.

[3] D. A. Terrar, C. M. Wilson, S. G. Graham, S. M. Bryant, and B. M. Heath, "Comparison of guinea-pig ventricular myocytes and dog Purkinje fibres for in vitro assessment of druginduced delayed repolarization," Journal of Pharmacological and Toxicological Methods, vol. 56, no. 2, pp. 171-185, 2007.

[4] C. Xu, S. Police, N. Rao, and M. K. Carpenter, "Characterization and enrichment of cardiomyocytes derived from human embryonic stem cells," Circulation Research, vol. 91, no. 6, pp. 501-508, 2002.

[5] S. E. Harding, N. N. Ali, M. Brito-Martins, and J. Gorelik, "The human embryonic stem cell-derived cardiomyocyte as a pharmacological model," Pharmacology and Therapeutics, vol. 113 , no. 2, pp. 341-353, 2007.

[6] H. Liang, M. Matzkies, H. Schunkert et al., "Human and murine embryonic stem cell-derived cardiomyocytes serve together as a valuable model for drug safety screening," Cellular Physiology and Biochemistry, vol. 25, no. 4-5, pp. 459-466, 2010.

[7] O. Caspi, I. Huber, I. Kehat et al., "Transplantation of human embryonic stem cell-derived cardiomyocytes improves myocardial performance in infarcted rat hearts," Journal of the American College of Cardiology, vol. 50, no. 19, pp. 1884-1893, 2007.

[8] L. W. van Laake, R. Passier, J. Monshouwer-Kloots et al., "Human embryonic stem cell-derived cardiomyocytes survive and mature in the mouse heart and transiently improve function after myocardial infarction," Stem Cell Research, vol. 1, no. 1, pp. 9-24, 2007.

[9] W. Dai, L. J. Field, M. Rubart et al., "Survival and maturation of human embryonic stem cell-derived cardiomyocytes in rat hearts," Journal of Molecular and Cellular Cardiology, vol. 43, no. 4, pp. 504-516, 2007.

[10] R. J. Hassink, A. B. de La Rivière, C. L. Mummery, and P. A. Doevendans, "Transplantation of cells for cardiac repair," Journal of the American College of Cardiology, vol. 41, no. 5, pp. 711-717, 2003.

[11] D. K. Singla, "Embryonic stem cells in cardiac repair and regeneration," Antioxidants and Redox Signaling, vol. 11, no. 8, pp. 1857-1863, 2009. 
[12] W.-H. Zimmermann and T. Eschenhagen, "Embryonic stem cells for cardiac muscle engineering," Trends in Cardiovascular Medicine, vol. 17, no. 4, pp. 134-140, 2007.

[13] H. Qiao, S. Surti, S. R. Choi et al., "Death and proliferation time course of stem cells transplanted in the myocardium," Molecular Imaging and Biology, vol. 11, no. 6, pp. 408-414, 2009.

[14] A. Gorbe, Z. Giricz, A. Szunyog et al., "Role of cGMP-PKG signaling in the protection of neonatal rat cardiac myocytes subjected to simulated ischemia/reoxygenation," Basic Research in Cardiology, vol. 105, no. 5, pp. 643-650, 2010.

[15] A. Görbe, Z. V. Varga, J. Pálóczi et al., "Cytoprotection by the NO-donor SNAP against ischemia/reoxygenation injury in mouse embryonic stem cell-derived cardiomyocytes," Molecular Biotechnology, vol. 56, no. 3, pp. 258-264, 2014.

[16] R. M. Bell and D. M. Yellon, "The contribution of endothelial nitric oxide synthase to early ischaemic preconditioning: the lowering of the preconditioning threshold. An investigation in eNOS knockout mice," Cardiovascular Research, vol. 52, no. 2, pp. 274-280, 2001.

[17] D. S. Burley and G. F. Baxter, "B-type natriuretic peptide at early reperfusion limits infarct size in the rat isolated heart," Basic Research in Cardiology, vol. 102, no. 6, pp. 529-541, 2007.

[18] T. I. Orbán, Á. Apáti, A. Németh et al., "Applying a'doublefeature' promoter to identify cardiomyocytes differentiated from human embryonic stem cells following transposon-based gene delivery," STEM CELLS, vol. 27, no. 5, pp. 1077-1087, 2009.

[19] K. Szebényi, A. Péntek, Z. Erdei et al., "Efficient generation of human embryonic stem cell-derived cardiac progenitors based on tissue-specific enhanced green fluorescence protein expression," Tissue Engineering_Part C: Methods, vol. 21, no. 1, pp. 35-45, 2015.

[20] J. Nichols, B. Zevnik, K. Anastassiadis et al., "Formation of pluripotent stem cells in the mammalian embryo depends on the POU transcription factor Oct4," Cell, vol. 95, no. 3, pp. 379391, 1998.

[21] Y.-H. Loh, Q. Wu, J.-L. Chew et al., "The Oct4 and Nanog transcription network regulates pluripotency in mouse embryonic stem cells," Nature Genetics, vol. 38, no. 4, pp. 431-440, 2006.

[22] I. Chambers, D. Colby, M. Robertson et al., "Functional expression cloning of nanog, a pluripotency sustaining factor in embryonic stem cells," Cell, vol. 113, no. 5, pp. 643-655, 2003.

[23] H. J. Fehling, G. Lacaud, A. Kubo et al., "Tracking mesoderm induction and its specification to the hemangioblast during embryonic stem cell differentiation," Development, vol. 130, no. 17, pp. 4217-4227, 2003.

[24] F. A. Stennard, M. W. Costa, D. A. Elliott et al., "Cardiac Tbox factor Tbx20 directly interacts with Nkx2-5, GATA4, and GATA5 in regulation of gene expression in the developing heart," Developmental Biology, vol. 262, no. 2, pp. 206-224, 2003.

[25] V. L. F. Linhares, N. A. S. Almeida, D. C. Menezes et al., "Transcriptional regulation of the murine Connexin 40 promoter by cardiac factors Nkx2-5, GATA4 and Tbx5," Cardiovascular Research, vol. 64, no. 3, pp. 402-411, 2004.

[26] H. Hirata, Y. Murakami, Y. Miyamoto et al., "ALCAM (CD166) is a surface marker for early murine cardiomyocytes," Cells Tissues Organs, vol. 184, no. 3-4, pp. 172-180, 2007.

[27] K. B. Walsh, T. C. Rich, and Z. J. Coffman, "Development of a high-throughput assay for monitoring cAMP levels in cardiac ventricular myocytes," Journal of Cardiovascular Pharmacology, vol. 53, no. 3, pp. 223-230, 2009.
[28] B. Ózsvári, L. G. Puskás, L. I. Nagy et al., “A cell-microelectronic sensing technique for the screening of cytoprotective compounds," International Journal of Molecular Medicine, vol. 25, no. 4, pp. 525-530, 2010.

[29] A. Nakano, G. S. Liu, G. Heusch, J. M. Downey, and M. V. Cohen, "Exogenous nitric oxide can trigger a preconditioned state through a free radical mechanism, but endogenous nitric oxide is not a trigger of classical ischemic preconditioning," Journal of Molecular and Cellular Cardiology, vol. 32, no. 7, pp. 1159-1167, 2000.

[30] J. Pálóczi, Z. V. Varga, Á. Apáti et al., "NO-donor SNAP protects human embryonic stem cell-derived cardiomyocytes against ischemia/reperfusion injury," in Proceedings of the Cost Action BM1005 Gasotransmitters Meeting, Conference Abstract, Messina, Italy, September 2015, http://real.mtak.hu/28715/.

[31] H. Takano, X.-L. Tang, Y. Qiu, Y. Guo, B. A. French, and R. Bolli, "Nitric oxide donors induce late preconditioning against myocardial stunning and infarction in conscious rabbits via an antioxidant-sensitive mechanism," Circulation Research, vol. 83, no. 1, pp. 73-84, 1998.

[32] Z. Xu, X. Ji, and P. G. Boysen, "Exogenous nitric oxide generates ROS and induces cardioprotection: involvement of PKG, mitochondrial KATP channels, and ERK," American Journal of Physiology-Heart and Circulatory Physiology, vol. 286, no. 4, pp. H1433-H1440, 2004.

[33] T. Uchiyama, H. Otani, T. Okada et al., "Nitric oxide induces caspase-dependent apoptosis and necrosis in neonatal rat cardiomyocytes," Journal of Molecular and Cellular Cardiology, vol. 34, no. 8, pp. 1049-1061, 2002.

[34] A. Hsieh, N. T. Feric, and M. Radisic, "Combined hypoxia and sodium nitrite pretreatment for cardiomyocyte protection in vitro," Biotechnology Progress, vol. 31, no. 2, pp. 482-492, 2015.

[35] S. Kanno, P. K. M. Kim, K. Sallam, J. Lei, T. R. Billiar, and L. L. Shears, "Nitric oxide facilitates cardiomyogenesis in mouse embryonic stem cells," Proceedings of the National Academy of Sciences of the United States of America, vol. 101, no. 33, pp. 12277-12281, 2004.

[36] P. Ferdinandy and R. Schulz, "Nitric oxide, superoxide, and peroxynitrite in myocardial ischaemia-reperfusion injury and preconditioning," British Journal of Pharmacology, vol. 138, no. 4, pp. 532-543, 2003.

[37] I. Andreadou, E. K. Iliodromitis, T. Rassaf, R. Schulz, A. Papapetropoulos, and P. Ferdinandy, "The role of gasotransmitters $\mathrm{NO}, \mathrm{H}_{2} \mathrm{~S}$ and $\mathrm{CO}$ in myocardial ischaemia/reperfusion injury and cardioprotection by preconditioning, postconditioning and remote conditioning," British Journal of Pharmacology, vol. 172, no. 6, pp. 1587-1606, 2015.

[38] S. P. D’Souza, D. M. Yellon, C. Martin et al., "B-type natriuretic peptide limits infarct size in rat isolated hearts via KATP channel opening," American Journal of Physiology: Heart and Circulatory Physiology, vol. 284, no. 5, pp. H1592-H1600, 2003.

[39] E. M. Abdelalim and I. Tooyama, "BNP signaling is crucial for embryonic stem cell proliferation," PLOS ONE, vol. 4, no. 4, Article ID e5341, 2009.

[40] T.-N. Wang, Y.-K. Ge, J.-Y. Li, X.-H. Zeng, and X.-X. Zheng, "B-type natriuretic peptide enhances mild hypoxia-induced apoptotic cell death in cardiomyocytes," Biological and Pharmaceutical Bulletin, vol. 30, no. 6, pp. 1084-1090, 2007.

[41] L. Zwi-Dantsis and L. Gepstein, "Induced pluripotent stem cells for cardiac repair," Cellular and Molecular Life Sciences, vol. 69, no. 19, pp. 3285-3299, 2012. 
[42] R. Madonna, P. Ferdinandy, R. De Caterina, J. T. Willerson, and A. J. Marian, "Recent developments in cardiovascular stem cells," Circulation Research, vol. 115, no. 12, pp. e71-e78, 2014.

[43] R. Madonna, L. W. V. Laake, S. M. Davidson, F. B. Engel, D. J. Hausenloy, and S. Lecour, "Position Paper of the European Society of Cardiology Working Group Cellular Biology of the Heart: cell-based therapies for myocardial repair and regeneration in ischemic heart disease and heart failure," European Heart Journal, Article ID ehw113, 2016.

[44] R. Madonna, F. B. Engel, S. M. Davidson et al., "Stem cell aging and age-related cardiovascular disease: perspectives of treatment by ex-vivo stem cell rejuvenation," Current Drug Targets, vol. 16, no. 8, pp. 780-785, 2015. 


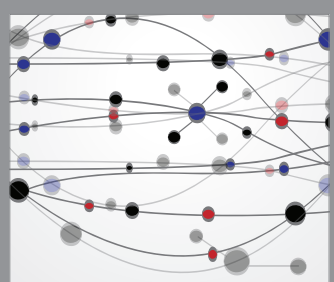

The Scientific World Journal
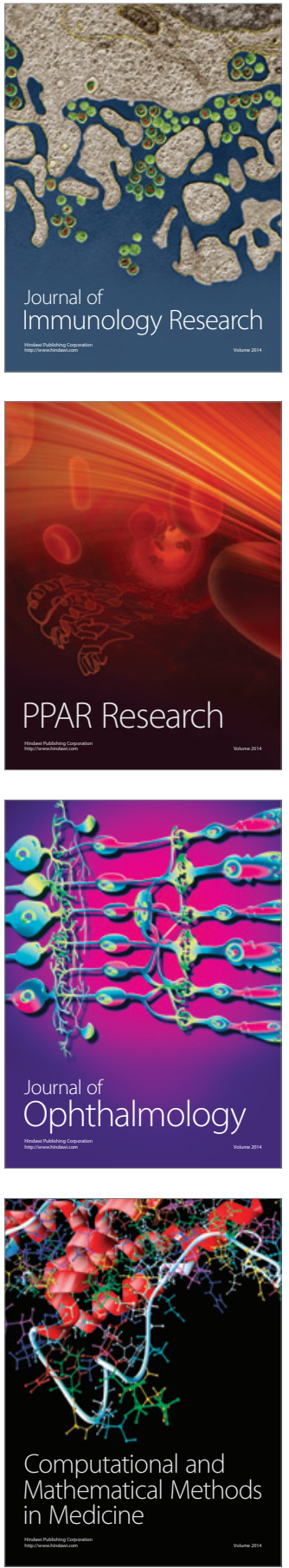

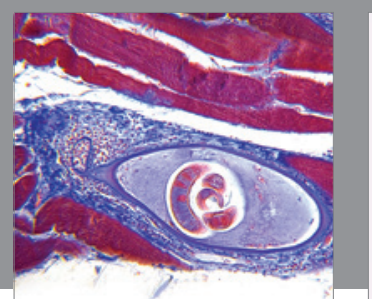

Gastroenterology Research and Practice

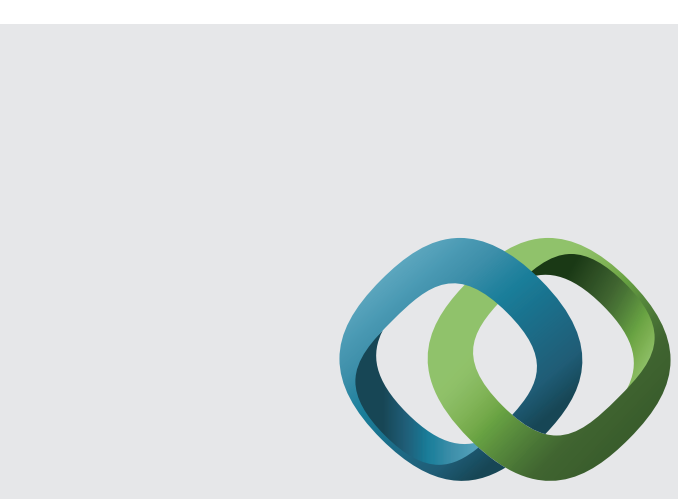

\section{Hindawi}

Submit your manuscripts at

http://www.hindawi.com
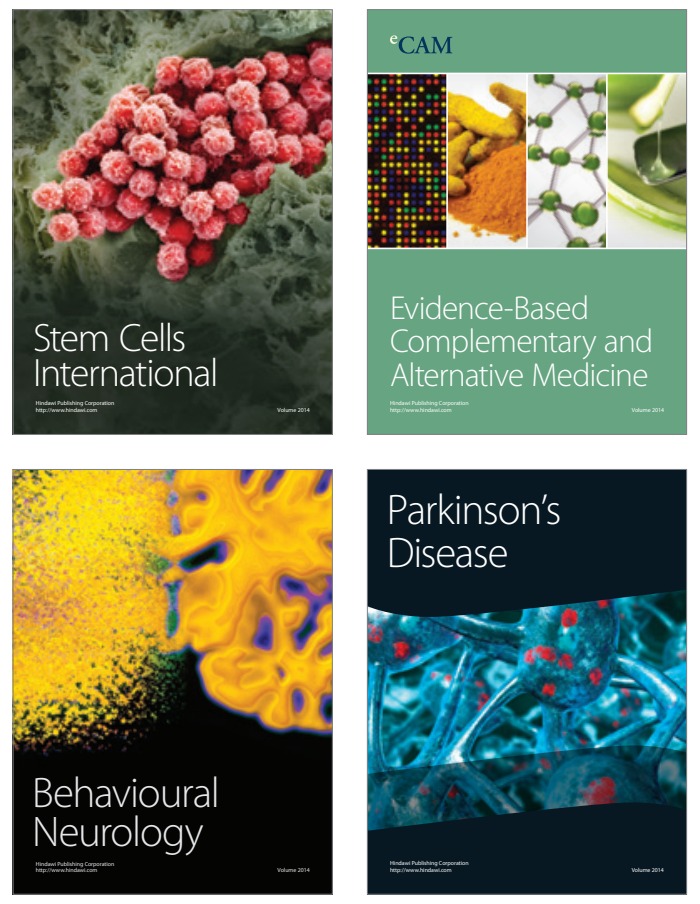
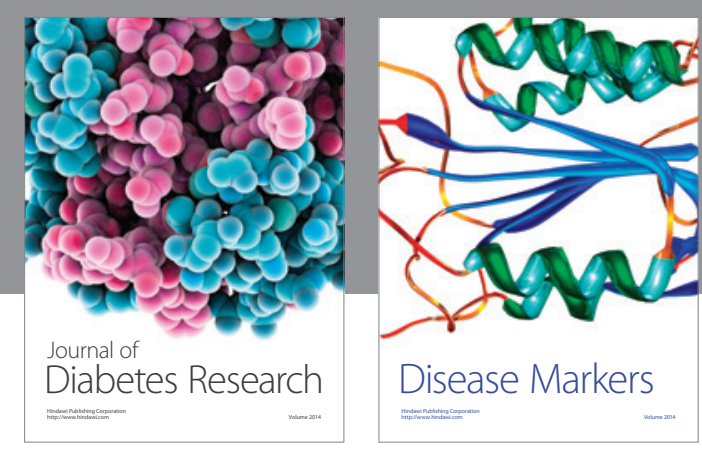

Disease Markers
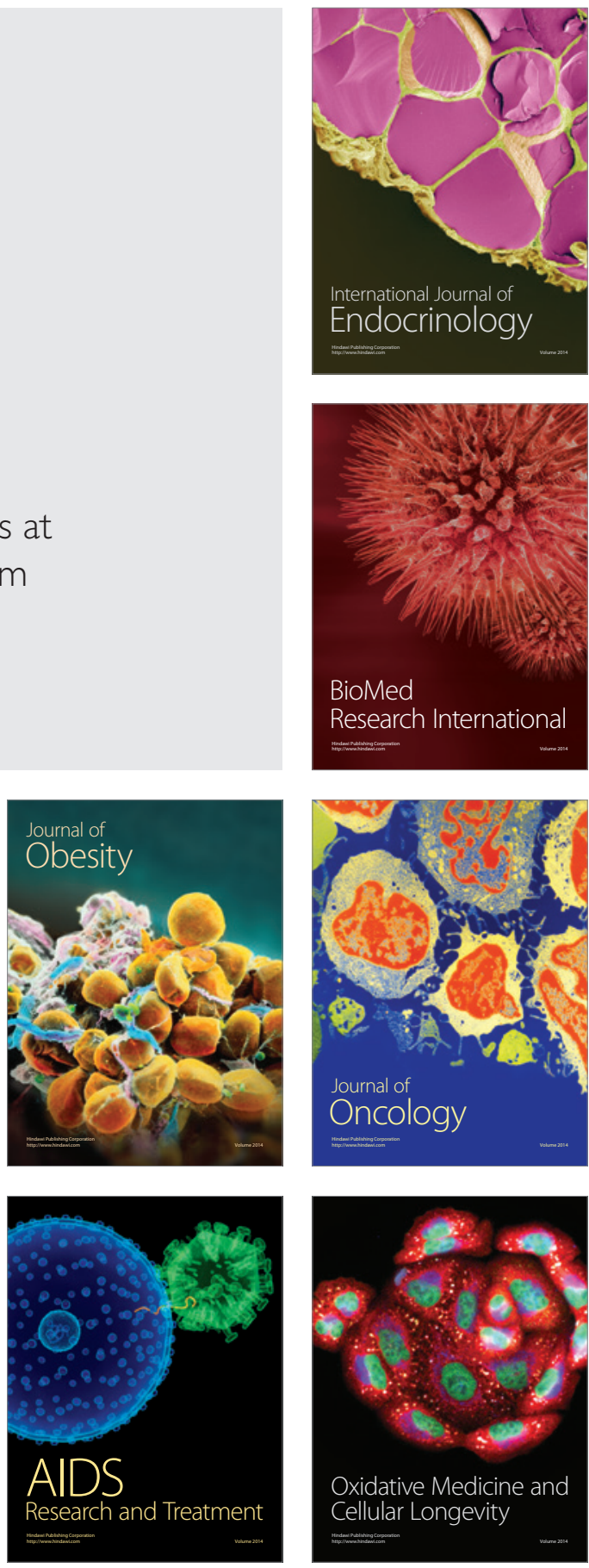